\title{
E-commerce Adoption in the Retail Sector: Empirical Insights
}

\author{
Ralitza Nikolaeva \\ School of Business Administration \\ University of Wisconsin Milwaukee \\ Milwaukee, WI 53201 \\ USA \\ e-mail: nikolar@uwm.edu
}

Acknowledgment: I would like to thank Hee-Kwon Jung for help with data collection, Amit Bhatnagar and Sanjoy Ghose for numerous fruitful discussions on the topic, and Laura Peracchio for editorial comments. All remaining mistakes are mine. 


\title{
E-commerce Adoption in the Retail Sector: Empirical Insights
}

Category: Research paper

\begin{abstract}
:
Purpose of this paper

To investigate the determinants of e-commerce adoption in the retail sector using duration analysis.

\section{Design/methodology/approach}

The study proposes a conceptual model based on technology adoption and population ecology models. It identifies specific determinant factors organized under three areas: perceived benefits, organizational readiness, and external influences. Duration analysis is applied to data on 392 retailers.
\end{abstract}

\section{Findings}

Organizational readiness and external influences were the main driving factors of the adoption decision. There is no strong support for the perceived benefits construct. This suggests that e-commerce adoption was to a great extent responsive to external pressures.

\section{Research limitations/implications}

Major limitations include insufficient data. Future research can collect other types of data. Other extensions include the investigation of the effect of e-commerce adoption, the construction of a formal theoretical model, and the collection of data from other countries.

\section{Practical implications}

The study provides guidelines to entry anticipation. It appears that many retailers mimetically responded to the online entry of other retailers. Managers should be also aware of the suitability of e-commerce adoption to their organization. In order to be proactive, firms can put more emphasis on internal factors and rely less on outside signals in their strategies.

\section{What is original/value of paper}

The paper investigates the e-commerce adoption decision among retailers using a unique database collected from public sources, avoiding potential subjectivity bias. It traces the timing of e-commerce adoption incorporating both fixed and time-varying covariates.

Keywords: density dependence, duration analysis, e-commerce, retailing 


\section{Introduction}

While Internet retail sales have increased tremendously in the past decade, they still represent a relatively small share of total retail sales. There are many retail firms that do not transact over the Internet yet. What distinguishes them from those who do? Zhu et al. (2003) point out that understanding the drivers and barriers of e-commerce adoption becomes increasingly important. Better insight into entry determinants can help companies in improving their strategies and coping with the impact of new entry. Therefore, awareness of the industry evolutionary dynamics is important both for new entrants and incumbents.

During the fledgling stage of e-commerce, the potential of the Internet agitated companies. Researchers were excited about the opportunities of the Internet as an efficient channel of distribution and communication (Hoffman and Novak, 1996). At the same time Ghosh (1998) reported that it was difficult for executives at most companies to estimate the value of their Internet investments. Thus, the Internet channel was considered quite risky and profit potential was uncertain. How did retailers react to the new market/channel opportunity? The e-commerce adoption decision in the retail sector was particularly risky because of the notoriously low profit margins in the sector (Hunter, 2003). For example, although on average IT's effects on financial performance are highly positive across industries (Hitt and Brynjolfsson, 1996), Hunter (2003) reports negative cumulative abnormal returns for publicly traded retailers to IT investment announcements. Then, the main question is: what were the key drivers of the timing of the e-commerce adoption decision? The purpose of this study is to provide some answers by investigating the factors influencing traditional retailers' timing of entry to the online channel.

The focal contention is that while the entry to the Internet channel of early adopters might have been driven by the pursuit of strategic opportunities, for the majority of retailers, external influences played a key role in the adoption decision. Using the theoretical 
framework of EDI (electronic data interchange) adoption proposed by Iacovou et al. (1995) and tools from the population ecology literature, this paper outlines and tests seven adoption related hypotheses. For the purpose, duration analysis is applied to data on 392 retailers.

\section{Theoretical Framework and Hypotheses}

O'Callaghan et al. (1992) organize the factors affecting the adoption of EDI technology in marketing channels into three groups: relative advantage, compatibility, and external influences. These three groups clearly correspond to the framework proposed by Iacovou et al. (1995). In their model EDI adoption is influenced by perceived benefits, organizational readiness, and external pressure. O'Callaghan et al. (1992) find that EDI adoption is primarily driven by the relative advantages perceived by firms to follow the adoption of EDI. Iacovou et al. (1995) distinguish between direct and indirect perceived benefits. The direct benefits come mostly from improved operational efficiencies. The indirect benefits are perceived more as opportunities like improved customer relationships or gaining a competitive advantage. Since e-commerce was surrounded by a lot of uncertainty and there were not clear measures of efficiency in the channel, it is more appropriate to assume that retailers looked at the new channel mostly in terms of opportunities. Further, an organization should be ready to adopt a new technology - firms with better financial and technological resources are more likely adopters. Finally, external influences refer to competitive pressures and impositions by trading partners or other constituencies. Iacovou et al. (1995) observe that among small businesses, external pressures are a very important factor in the adoption decision. Grandon and Pearson (2004) summarized the technology adoption literature and find that external influences are fairly persistent across different studies. 
Zhu et al. (2003) apply the technology-organization-environment (TOE) theoretical framework to the adoption of electronic business at the firm level in eight European countries. They provide a summary of studies using the TOE framework and show the similarities of constructs used in various studies on EDI and IS adoption by firms. The authors observe the similarities with e-business adoption, which justify the use of this framework: e-business is enabled by the technological development of the Internet, and it is driven by organizational and environmental factors. They find that technology competence, firm scope and size, consumer readiness, and competitive pressure are significant adoption facilitators. In addition, the TOE framework has consistent empirical support, which provides a good base for comparisons.

While adopting the above theoretical framework, this study differs from previous ones in the hypotheses testing method. Whereas past studies have used survey or case method research to test their hypotheses, the current one uses tools from the population ecology literature, namely duration analysis, to estimate the effects of various factors on data collected exclusively from public sources. Secondary data are free from respondents' subjectivity, but at the same time they provide limited information on some important constructs. The advantages and disadvantages of the data are discussed in the limitations section of the paper. With the above discussion, the framework describing the factors influencing the entry to the online channel of retail firms is organized as follows: 1) perceived benefits/relative advantage - expectations of opportunities reflected by market growth, the general economic and technological climate, and advertising intensity as barriers to entry; 2) organizational readiness/compatibility - firm size and product-channel fit; 3) external influences - population density dependence, and information from the stock market for publicly traded companies. The conceptual model is illustrated in Figure 1 . The rest of the section discusses each of these factors and presents the hypotheses associated with them. 
[Take in Figure 1.]

\section{Perceived Benefits}

Economic theory holds that the market entry decision for a firm is determined by the profitability of the market and barriers to entry (Geroski, 1995). One of the classic textbook examples is that the number of firms at any given point in time is proportional to the size of the market (Geroski and Mazzucato, 2001). A market characterized by high growth rates usually attracts many new entrants and causes optimism about the industry (Aaker and Day, 1986). The Internet channel was characterized by very high growth rates, which probably prompted many established retailers to enter the online market. Therefore, we would expect:

H1: Market growth rate positively affects retailers' probability of entry to the Internet channel.

For firms, the stock market is a signal of market expectations for future demand. Jovanovic and MacDonald (1994) describe the tire $\left[{ }^{1}\right]$ industry immediately after World War I when expectations of industry growth were very high. This led to inflated stock prices of tire companies resulting in high entry rates. The NASDAQ index is comprised of many technology companies. Thus any major technological developments would be reflected by the NASDAQ composite index. The NASDAQ index can signal also overall stronger economic milieu. Golder and Tellis (2004) hypothesize that a change in the economic environment would cause a change in sales in the same direction. By the same token, a change in the NASDAQ index should accelerate the timing of entry - positive changes should signal positive demand expectations, which should drive higher entry rates. This leads to the following hypothesis:

H2: NASDAQ growth rate positively affects retailers' probability of entry to the Internet channel. 
Another important factor influencing entry is advertising intensity in the industry. Sutton (1991) argues that advertising intensity in an industry can act as barriers to entry. When advertising intensity is high, many firms have high advertising expenditures and high sunk costs lead to less entry. If this is the case, advertising intensity would be an inhibitor to the adoption of the online channel. Latcovich and Smith (2001) show that advertising costs in online bookselling are endogenous. This means that as the market expands, advertising expenditures rise and this discourages entry of new firms (Latcovich and Smith, 2001). However, higher advertising intensity may grow the size of the market making it more cost effective for new firms to pay the higher cost of entry since now the potential returns are higher. This limits the effect of advertising as an entry barrier. In this sense, we would expect industry advertising expenses to have a negative effect on the probability of entry with a second order positive effect. Thus:

H3: There is a U-shaped relationship between advertising intensity and retailers' probability of entry to the Internet channel.

\section{Organizational Readiness/Compatibility}

What is the importance of retailer's size in the entry decision? Zhu et al. (2003) report that firm size has been consistently recognized as a factor affecting technology adoption. Since the entry decision is related to capital resource requirement, it is expected that bigger firms would be more likely to enter the online channel. As outlined by Zhu et al. (2003), larger firms are more likely to achieve economies of scale that would bring faster return on their e-commerce investment (this effect is also observed by Wu et al. (2003)), they have more resources to bear the early risks associated with the uncertainty of the e-commerce investment and have more power in negotiating favorable terms with trading partners. Large firms have been also shown to receive better financing terms and to have better opportunities 
to hire more talented employees (Mazzucatto, 2000). Big retailers are also more likely to capitalize on the cross-channel experiences of their customers. Therefore:

H4: Firm size affects positively retailers' probability of entry to the Internet channel.

Keeney (1999) shows that one of the values of Internet commerce to consumers is product information, hence companies' objective should be to maximize product information. The Internet channel presents a better opportunity to maximize product information for certain product categories. Such products are more often search rather than experience goods (Mahajan et al., 2002), good gift items, and easy to transport. For these products physical attributes like smell, taste, and freshness are not important (Lal and Sarvary, 1999). For example, De Figueiredo (2000) classifies books, CDs, and videos as quasi-commodity group of products based on consumers' ability to judge their quality. Because consumers are able to judge their quality regardless from where they are sold, they would sell well over the Internet. Further, electronic and related products are also more likely to fit with the channel (Hart et $a l ., 2000)$. This is because of the predominant demographic characteristics and interests of early Internet users, the possibility to transmit plenty of information about the product, and the opportunity to comparison shop. In addition, companies that have prior experience with non-store retailing like catalogue retailers are also more likely to embrace the Internet faster, because of the experience in fulfillment and distribution that they have accumulated. The product categories in the database that possess the above mentioned characteristics are nonstore retailers, electronics, and specialty. Because these products offer a better fit to the online channel, retailers in these categories should be more likely to open online stores earlier. This yields:

H5: Retailers whose products fit better the online environment have a higher probability of entry to the Internet channel compared to other retailers. 


\section{External Influences}

Firms imitate each other. This phenomenon has been largely documented in various theoretical and empirical studies in economics, management and organization theory (Lieberman and Asaba (2005) present an overview of various studies in these streams). Lieberman and Asaba (2005) organize the business imitation literature in two categories: information-based and rivalry-based theories. Under the information theory, imitation occurs, because firms perceive other firms to have more information. Under the rivalry theory, firms' behavior converges either to maintain competitive parity or to reduce rivalry. According to the authors' dichotomy of environmental conditions, under high uncertainty/ambiguity of the market and technology, information-based imitation is expected to prevail. Since the online channel was characterized by high uncertainty, the study focuses on these theories to offer an explanation of the observed rates of Internet channel adoption by retailers.

The herd behavior literature, which is the backbone of the information-based stream, was started by Banerjee (1992) and Bikhchandani et al. (1992) who model the individual's information acquisition by observing the behavior of others. When individuals face uncertainty they assume that the agents who took a certain action before them did so because they had more information. As a result, each agent follows in the steps of the predecessors regardless of their own information.

The organization theory stream that draws on population ecology and is related to information cascades deals with legitimacy of the industry (Hannan and Carroll, 1992). Founding rate increases with legitimacy and decreases with competition. The process of legitimation continues until a saturation point is reached when competitive effects related to limited resources in the market take an effect. This is usually when a shakeout in the industry occurs. The population ecology perspective provides a good framework to capture the time related nature of entry and the competitive behavior of firms in an evolving market (Ozsomer 
and Cavusgil, 1999). Numerous studies have confirmed the positive relationship of entry and entry rates or population numbers followed by a second order negative relationship (for an overview see Delacroix and Rao, 1994).

Delacroix and Rao (1994) offer vicarious learning as part of the explanation of density dependence. They define vicarious learning as learning by imitating what others do or avoiding others' mistakes. The greater the number of firms, the greater the opportunities to learn. This is especially important when environmental uncertainty is high, which is the case with e-commerce. Therefore, it is expected that a strong density dependence effect will be observed in retailers' entry to the online channel. Imitating other firms' behavior may help legitimize the actions of managers who are pressed to make decisions with limited information concerning the outcome of their actions.

These indicators lead to the expectation that as more retailers open Internet stores, the channel becomes more attractive prompting even higher entry rates. Entry rates do not increase forever, however. At some point competitive effects become stronger and entry stops being so attractive. The numerous firms with online presence start fighting for the same resources and this may raise the barriers to entry. Subsequently, the entry rates decrease. This leads to the following hypothesis:

H6: There is an inverted-U type relationship between population density and retailers' probability of entry to the Internet channel.

Publicly traded companies are influenced by numerous shareholders and are more often in the public eye. Maug (2001) states that publicly traded companies have an advantage when outside investors have better access to information that is useful for future capital budgeting decisions. This is when industry information is more important. The author's point is that publicly traded firms can use the information aggregated by the stock market and communicated back to the firm by the stock price. Eventually, this information helps the firm 
make more informed decisions. Wu et al. (2003) point out that when market uncertainty is high, businesses tend to gather more information from the environment in order to better predict future market trends. Since e-commerce represented such a risky environment, firms required plenty of outside information to judge its potential. Consequently, publicly traded companies could have been in possession of better information.

High growth markets often create asymmetry in perceptions - the potential profits loom larger than the risks associated with high growth and turbulences. That is why publicly traded companies face high risks if they miss high growth opportunities. Along the same lines, managers in publicly traded companies are accountable to more constituencies. Wu et al. (2003) discuss that organizations may adopt innovations on account of powerful constituencies. Therefore managers at publicly traded companies may risk more if they are perceived as laggards in the adoption of an innovation that is fairly common in the public eye. Further, if the market favors the new technology, as was the case with e-commerce, they can raise even more capital to adopt the new technology. On the other hand, privately held firms do not face this pressure from shareholders. Consequently, they may be able to make more calculated decisions and take more time to execute them. Thus, it is expected that publicly traded retailers would be more likely to adopt the online channel earlier.

H7: Publicly traded retailers have a higher probability of entry to the Internet channel compared to privately held retailers.

Table I summarizes the hypothesized relationships.

[Take in Table I.]

\section{Data Description}


The data were assembled from several public sources. The list of retailers comes from the Hoover's database, which provides comprehensive information about firms in different industries. The entry event is defined as the point in time when a retailer starts transacting with customers over the Internet. The period of time spans January, 1995 to March, 2003, because the first entry is in the first quarter of 1995 . The information on market entry dates comes from company websites, annual reports, and news stories from the Lexis-Nexis business news database. Observations for which the entry date information was not available were deleted from the sample.

The market growth data come from the Bureau of Census. $\left[^{2}\right]$ Quarterly closing NASDAQ index values come from Yahoo! Finance. The difference from the previous quarter is taken to reflect the growth rate. The Internet Advertising Bureau (IAB) sponsors quarterly surveys to determine the amount of advertising dollars spent by businesses on the Web. The report aggregates data and information reported directly to PricewaterhouseCoopers by companies representing thousands of websites and other online selling companies.

The Hoover's database also provides information about whether a firm is publicly traded or not, whether a firm has a physical store, catalog or a TV channel, retail categories, and sales data for 2002. For some firms, sales data for 2002 were missing and these were deleted from the sample. The retail categories that fit the product-channel fit description are non-store retailers, electronics, and specialty. The specialty category is rather broad and it includes primarily retailers of books, music, and video, as well as computers, gifts, and toys. This resulted in a final sample of 392 retailers about whom we know whether they have online operations, whether they are publicly traded, sales data for 2002, type of store, and the location of their headquarters.

\section{Description of Variables}


The dependent variable is a binary variable indicating whether a retailer transacts over the Internet channel. The beginning of the observation period is January 1995. Out of 392 retailers in the sample, 185 were transacting over the Internet by the end of the observation period - March 2003.

The market growth rate is operationalized as the difference of quarterly sales in the electronic shopping and mail order category in the databases provided by the US Bureau of Census. In order to soften the holiday season effect, a moving average of the differences in three quarters is taken. Market expectations and economic conditions are reflected by the change in the lagged closing NASDAQ values at the end of each quarter from the previous quarter. The quarterly Internet advertising revenues are also lagged. To account for the growing mass of the industry, the quarterly advertising spending is divided by the number of firms in the market in that quarter.

The standardized 2002 sales figures are used as a proxy for size. Sales are standardized by dividing the retailer's sales by the average in its respective category. This is done in order to avoid discrepancies between different categories. Product-channel fit is a dummy variable with the value of 1 for retailers in the non-store, electronics, and specialty categories.

The density effect is captured by the cumulative number of retailers within a category in the previous quarter. The square term of the cumulative number of retailers within a category captures the overcrowding competitive effect. Publicly traded companies are coded as " 1 ".

Since $17 \%$ of the retailers in the sample have headquarters outside of the US, the model includes a control dummy variable for international retailers. Given the faster pace of e-commerce development in the US, it is expected that international retailers would be slower 
in the e-commerce adoption decision compared to US retailers. Such differences are reported in other studies described in Hart et al. (2000).

\section{Descriptive Statistics}

The data were organized into quarters, because advertising and market growth data are available on a quarterly basis. This resulted in a sample of 10,251 firm-quarter observations. Details regarding the data are presented in Figure 2 and Tables II and III. There are a total of 392 firms in the sample. The percentage of retail firms that have set up Internet based stores by the end of study are $47 \%$. Almost four-fifth of the firms in the sample are publicly traded. One-third of the categories are a good fit for retailing on the Internet channel. Table II contains the descriptive statistics and the correlations of the variables used in the estimation procedure.

\section{[Take in Table II.]}

Figure 2 plots the frequency of entry of firms by quarter. We can see that the frequency slowly increased, peaked around $18^{\text {th }}$ quarter, which corresponds to mid 2000 and then declined. And Table III compares the entry rates between different groups of retailers. First, we observe that the 5 year entry rate in the whole sample was only $29 \%$. The picture is quite different when we compare big vs. small firms (small firms have standardized sales values less than 1 and big firms more than one), publicly traded vs. private, and retailers whose products fit the Internet channel vs. retailers in other categories. The entry rate 5 years into the observation period for big retailers is almost $42 \%$ - quite higher compared to the average of the sample and to the rate of small retailers $(25 \%)$. The difference between product fit categories and others is similar $-44 \%$ entry rate vs. $22 \%$. Although not as dramatic, a significant difference exists in the entry rates between publicly traded and private firms, where as hypothesized, the entry rate for publicly traded retailers is higher. 
[Take in Figure 2 and Table III.]

\section{Model Specification and Estimation}

While we know when retailers started transacting over the Internet, we don't know when the ones who did not by the end of the observation period will open an online store. Thus, these observations are censored. Duration analysis - a common technique in the population ecology literature - makes full use of the available information in the case of censored observations.

Further, we do not have a theoretical foundation predicting the pattern of retailers' adoption of the online channel. According to Allison (1995), there are two approaches that can be followed when there is no theoretical basis for the shape of time dependence. One is to use a Cox proportional hazards regression and use the partial likelihood method to estimate the variable coefficients. In this way any information of time dependence is discarded. The second approach is to estimate the same model with maximum likelihood techniques using a logit or cloglog link and the inclusion of time variable in the model. Since advertising is collected on a quarterly basis, the data is grouped into quarters, which makes a discrete hazard model a more attractive alternative. The hazard rate is the probability of entry in the next interval of time conditional on not having opened an online store up to that time. The logit and cloglog regressions also allow for the easy incorporation of time-varying covariates. The cloglog specification assumes proportional hazards (the cloglog regression is the discrete time equivalent of the Cox proportional hazards regression), whereas the logit specification does not (Jenkins, 1995).

If entry does not depend on how much time it has passed since the beginning of the observation period, then the hazard of entry is duration independent. If this is not the case, 
then the estimation should allow for duration dependence. There are different ways to model time dependence. In general, time dependence per se is not a valid concept. By incorporating time as a covariate we assign explanatory power to time, which as pointed by Cleves et al. (2002) is absurd. Incorporating time in the model is a way to proxy other effects that we either cannot measure or we do not understand. One way to incorporate time dependence is to include time-periods dummy variables in the model, which allows for flexibility in the time dependence function. However, incorporating dummy variables for each of the time periods in the sample will result in an unnecessary cumbersome model. For this reason the time periods are aggregated into years with a dummy variable for each year in the sample.

In order to estimate the discrete duration models, the data are organized into firmquarter observations. For each quarter we have information on market and NASDAQ growth rates and quarterly advertising expenditures accounting for the perceived benefits or inhibitors of adopting the online channel. In terms of external influences we also know the number of retailers who have already opened online stores in the preceding quarter broken by categories. The time-invariant covariates that stay the same in each quarter are firm size, product category fit, whether the firm is publicly traded or not, and whether the firm has international headquarters.

Both the logit and the cloglog regression estimate the probability of entry in the particular time period. The specifications are presented below.

Logit:

$$
\log \left(\frac{h_{i t}}{1-h_{i t}}\right)=X_{i t} \beta+\lambda_{t}
$$

Cloglog:

$$
\log \left[-\log \left(1-h_{i t}\right)\right]=X_{i t} \beta+\lambda_{t}
$$


Where $\lambda_{t}$ is the baseline hazard, $X_{i t} \beta$ is a vector of covariates. Since there are 33 quarters in the data, $t$ assumes values from 1 to 33 and $i$ stands for company. A positive $\beta$-coefficient implies that the corresponding covariate increases the conditional probability of entry. More specifically, when the covariate changes by 1 unit, the probability changes by $[\exp (\beta)-$ 1)]*100 percent. A set of time-varying dummy variables describes the time dependence. Positive coefficients indicate a higher entry rate compared to the first year. This is a nonparametric approach to modeling time dependence (Dekimpe et al., 1998). The models are estimated with STATA using the cluster option to account for dependency in multiple firm-quarter observations. The cluster option specifies that observations are independent between groups, but not among groups. The estimation uses the Huber/White/sandwich estimator of variance. Thus, the right hand side of the above equations is:

$$
\begin{aligned}
& \beta_{1} \text { marketgrowth }_{t}+\beta_{2} \text { NASDAQgrowth }_{t}+\beta_{3} \text { ad }_{t}+\beta_{4} \text { ad }_{t}{ }^{2}+\beta_{5} \text { size }_{i}+\beta_{6} \text { productfit }_{i}+ \\
& \beta_{7} \text { density }_{i t}+\beta_{8} \text { density }_{i t}{ }^{2}+\beta_{9} \text { public }_{i}+\beta_{10} \text { international }_{i}+\lambda_{j}
\end{aligned}
$$

where $j=2$ for $t \in[5,8], j=3$ for $t \in[9,12], j=4$ for $t \in[13,16], j=5$ for $t \in[17,20], j=6$ for $t \in[21,24], j=7$ for $t \in[25,28], j=8$ for $t>28$.

Standard duration models assume that all retailers in this study will eventually enter the online channel. However, we don't know whether this is true. Some retailers might never open an Internet store. For such cases, it is best to use a split population duration (SPD) model. This model helps us weigh the likelihood of each observation by the probability of entry to the online channel and in this way the duration analysis is applied only to the retailers who are predicted to open online stores. To illustrate the logic behind the SPD model, let's say a retailer opens an online store in March 1999. Then we have observed this retailer for 13 quarters when it exits the sample. For a retailer who does not open an online store by the end of the observation period, we don't know whether it will ever do so. Standard duration models treat this retailer as a censored observation assuming that at a 
certain point of time it will enter, but we don't know when. The SPD model splits the censored group of observations into two groups - one consists of retailers whose probability of entry is very small, hence they are considered "non-entrants"; the other group are the ones who will eventually adopt the online channel. Thus, using maximum likelihood we can estimate the proportion of "non-entrants" and the parameters of the hazard rate on the remaining observations in the sample.

Jenkins (2001) has written a code for the estimation of the SPD model with discrete data in STATA based on the following model (Jenkins, 2001). If we define an indicator of entry as $E=1$, then $E=0$ means that a retailer never enters the online domain. Then we can define the probability of entry as $\mathrm{p}(\mathrm{E}=1)=1-c$ and $\mathrm{p}(\mathrm{E}=0)=c$ as the probability of non-entry. For the retailers that we have observed to have opened online stores, the contribution to the likelihood function is $(1-c)^{*}$ (probability of survival to the end of the previous quarter)*(probability of entry in the current quarter). For the retailers who are not observed to enter by the end of the observation period, the ones who will never enter contribute $c$ to the likelihood function and the rest contribute $(1-c)^{*}$ (probability of survival to the end of the given quarter). This results in the following log-likelihood function:

$$
\ln L_{i}=d_{i} \ln \left[(1-c)\left(S_{i t}-1\right) h_{i t}\right]+\left(1-d_{i}\right) \ln \left[c+(1-c) S_{i t}\right]
$$

where $S_{i t}$ is the discrete-time survivor function, $d_{i}$ is a censoring indicator equal to 1 if the retailer has been observed to open an online store, 0 otherwise, and the discrete time hazard $h_{i t}$ takes the cloglog form.

\section{Empirical Results}

The coefficient estimates obtained by calibrating the discrete hazard models with logit and cloglog links are presented in Table IV. Model 1 uses a logit link and Model 2 - a 
cloglog link. We can see that Models 1 and 2 provide extremely close results, which are practically indistinguishable.

[Take in Table IV.]

\section{$\underline{\text { Perceived Benefits }}$}

Based on the estimation results, it seems that the rapid growth of the market did not stir retailers to action. The NASDAQ growth rate reflecting market expectations and overall stance of the economy does not seem to have a significant effect either. Thus, neither H1 nor $\mathrm{H} 2$ are supported. The coefficients of advertising expenditure are slightly significant in the hypothesized direction. Increasing advertising expenditures in the online channel has a deterring effect on retailers' entry, but the effect diminishes with the growth of the market. In this case advertising expenditure is interpreted as entry barriers whose effect diminishes overtime. Hence, H3 is weakly supported.

\section{Organizational Readiness}

As hypothesized (H4), retailer size affects positively the likelihood of opening an online store. This result has been largely observed in previous studies (Zhu et al., 2003). Also, retailers offering products that are a better fit to the online environment are more likely to speed up the opening of online stores. More precisely - they are more than two times more likely to start online operations $(\exp (0.73)=2.08)$. Both coefficients are highly significant thus supporting H4 and H5.

\section{$\underline{\text { External Influences }}$}

As predicted, the density variable increases entry and the second order polynomial indicates diminishing effects. That is, it appears that retailers tend to speed up their entry to the online channel when they witness increasing density in their respective categories. At some point, however, the effect reverses, because the environment becomes very competitive. 
The observation of one additional entrant in retailers' own category in the previous quarter increase the probability of entry by $5 \%$. The results come in direct support of H6.

Finally, H7 is also supported - publicly traded companies under the pressure of shareholders and the market seem to be more likely to open online stores. The coefficient is significant at 5\% level indicating that publicly traded retailers are about 1.65 times more likely to adopt the online channel.

International firms, as expected, are less likely to adopt the online channel. However, the representation of international retailers in the sample is quite small and the results are in no way conclusive on this issue.

The results from the estimation of the SPD model are presented in Table V. The estimated probability of never opening an online store is so small that there is no difference between the SPD model and the cloglog model, which assumes that the $c=0$. Thus the results from the SPD model do not change the above discussion. $\left[{ }^{3}\right]$

[Take in Table V.]

\section{Discussion and Conclusion}

The study proposes a conceptual model of existing retail firms' online entry determinants based on the combination of technology adoption and population ecology theoretical frameworks. The major findings indicate that organizational readiness and external influences are the main drivers of the online adoption decision. Perceived benefits do not seem to exert much influence on e-commerce adoption. This is surprising, because according to economic theory perceived benefits should be the main driving force. However, as observed by Geroski (1995) similar results surface often in empirical studies. These findings echo Geroski and Mazzucato's (2001) observation that firms often fail to pay 
significant attention to economic indicators. Of course, we do not have access to the type of information that firms were using regarding their adoption decision, so this interpretation is somewhat speculative. However, Wu et al. (2003), whose study is based on a managerial survey, do indicate that external pressures without well-reasoned economic objectives were a significant antecedent of e-business adoption. Thus, the interpretation that economic indicators do not appear to be strong determinants of e-commerce adoption does not seem to be out of line with the existing literature.

On the other hand, organizational readiness plays a significant role in the adoption decision. Larger retailers and retailers selling products that offer a better fit to the online channel exhibit a higher likelihood to set up Internet stores. Larger retailers have more resources to carry-out the risks associated with Internet adoption. They are also more likely to have better access to human capital, trading partners, a larger customer base that can be tapped for cross-channel promotions, and they are at a higher risk of being perceived as technological laggards if they do not engage in e-commerce. Further, retailers who offer universal, low-risk, information and/or technology intensive and easy to distribute products are more likely to adopt the Internet channel.

As observed in previous studies (Zhu et al., 2003), external influences play a major role in the e-commerce adoption decision. Based on the results, we can be fairly sure of the presence of a density effect. Increasing density tends to speed up the process of opening of online stores. The effect is accompanied by a second order term of the opposite sign, which indicates congestion effects - as density grows beyond a certain point, the market stops being attractive and competitive effects set in. In the context of the online setting, which was characterized by high environmental uncertainty, density dependence can be interpreted as herd behavior (Lieberman and Asaba, 2005). Greve (1996) discusses how the presence of uncertainty might motivate companies to engage in mimetic adoption even when positive 
payoffs for early entrants are not observed. This discussion seems particularly applicable to the Internet channel. Retailers are influenced by population movements and the probability of online entry is positively related to these movements. Also, publicly traded companies that were in a position to better utilize external information appear to have shortened the timing of online entry.

\section{Limitations and Future Research}

The major limitations of this study originate from the fact that it is based on secondary data. Because of this, the operationalization of some of the constructs is far from perfect. Also, the limited availability of secondary data precludes the inclusion of other important factors like financial health of the retailers, innovation capabilities, organizational culture, relationship with suppliers, etc. Future research can test the validity of the findings through other types of data, such as survey or experimental research.

This study can be extended along several directions. Future research can look at the effect of e-commerce adoption. When retailers followed other retailers in the adoption decision, did they do it because they could observe the benefits for the adopters or did they blindly imitate assuming that such benefits existed? This would help separate and differentiate more clearly the perceived benefits of adoption from the density effect. Another extension would be to provide a formal theoretical model of conditions under which different factors exert different influence on the adoption decision and test the predictions with the available data. Finally, data from other countries can be gathered to see whether the findings are robust across different markets. Currently the sample has only $17 \%$ internationally based retailers. A study across different countries and cultures would greatly enrich the findings and their generalizability. 


\section{Managerial Implications}

The study provides guidelines to entry anticipation. Such guidelines are important both to firms who are contemplating an entry decision and to incumbents who want to prepare for and respond to new entry. The findings indicate that managers in the retailing industry are susceptible to external influences. This can be good or bad. It can be bad in the case when action is being taken without adequate foresight into the economic consequences. As $\mathrm{Wu}$ et al. (2003) find out, e-business initiatives adopted under normative external pressure did not yield significant performance improvements across four technology-intensive industries. This can result in missed strategic opportunities and readjustment to reactive rather than proactive strategic actions.

Further, managers should be aware of the suitability of e-commerce adoption to their organization. Retailers with more resources and products fit to the online channel have the opportunity to be more proactive and achieve better penetration in the online market. This could lead to future efficiency and better profits.

Increasing entry rates signal a positive feedback that can be expected to continue until competitive effects become too strong. One way for incumbents to discourage new entry is to increase advertising expenses. Further, firms can modify their entry strategies by putting more emphasis on internal factors and predictions and rely less on outside signals. An alternative approach would be to calculate the cost of not joining "the herd." Such costs include forfeited market opportunities and the stigma of being a technological laggard, which can have negative repercussions originating both from shareholders and customers. Then, it is possible that imitation is the less costly option.

\section{Conclusion}


The study proposed a theoretical framework for the investigation of the adoption of ecommerce in the retail sector. Using duration analysis, it tests the model using data on 392 retailers collected from secondary sources. The unique longitudinal dataset allows for tracing the determinants' effect over time - something that is usually not feasible with survey industry data. Five out of the seven hypothesized relationships were confirmed. The major findings indicate that organizational readiness and external influences are more important for the entry decision than perceived benefits. Surprisingly, retailers' e-commerce adoption did not seem to be primarily driven by high growth market rates or expectations. This implies that many firms adopted the online channel as a reaction to observed actions of other firms. More research is necessary to evaluate the outcomes of these decisions. It would be particularly interesting to see whether firms viewed these actions as a strategic opportunity or a strategic necessity and to what extent the outcome differed based on the framework of the adoption decision. 


\section{Figure 1}

Conceptual model of online entry determinants.

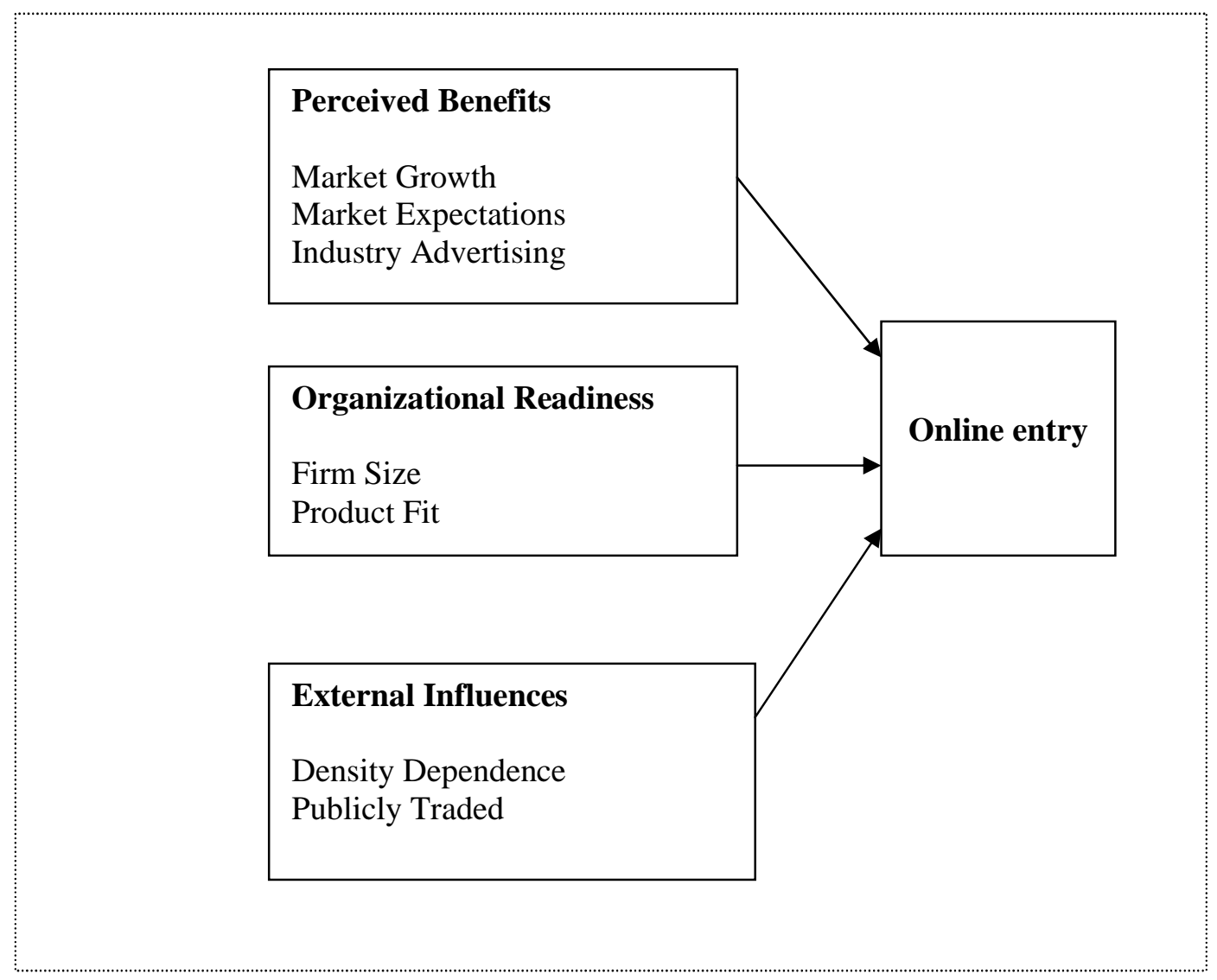


Figure 2

Entry frequency by quarter

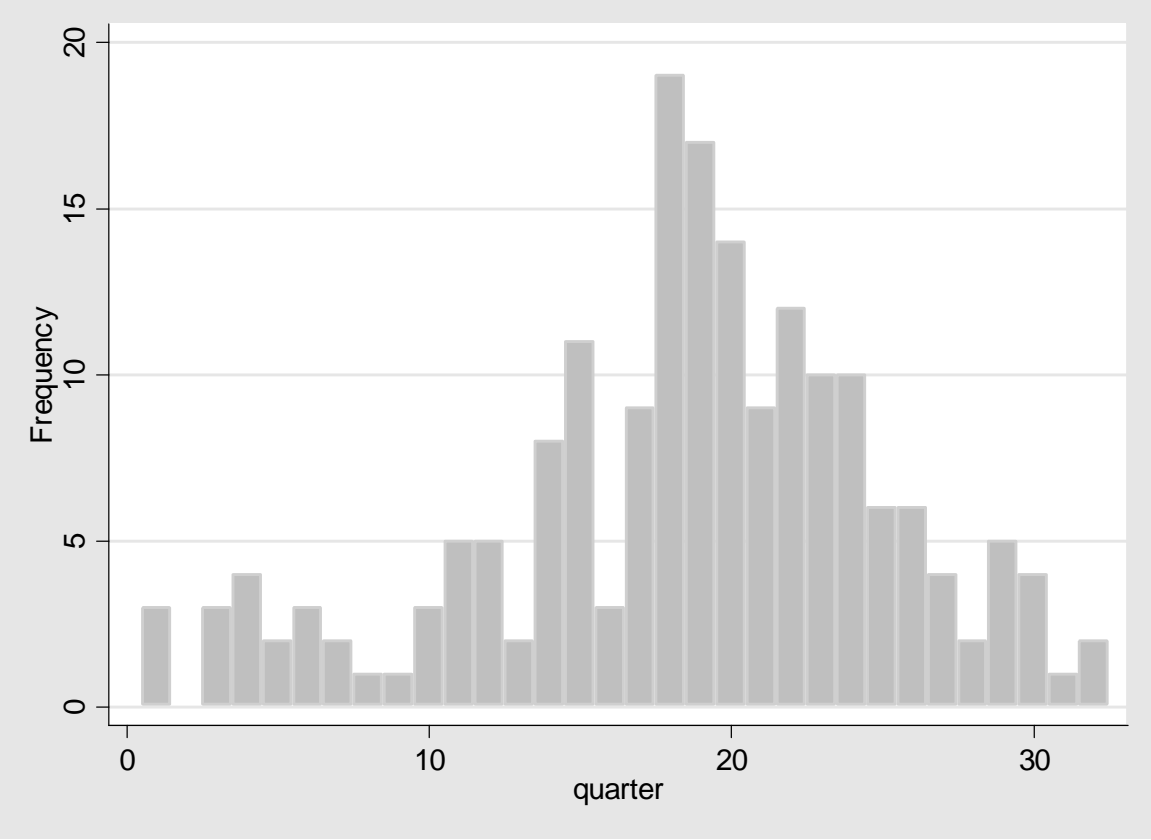


TABLE I

Expected relationships

\begin{tabular}{llc}
\hline \multicolumn{1}{c}{ Determinant Factors } & \multicolumn{1}{c}{ Expected Relationships } & $\begin{array}{c}\text { Predicted } \\
\text { Coefficient Sign }\end{array}$ \\
\hline Perceived Benefits & & + \\
Market growth rate (H1) & Increases probability of entry. & + \\
NASDAQ growth rate (H2) & Increases probability of entry. & + \\
Advertising (H3) & Negative effect on probability of entry. \\
Advertising Sq. (H3) & $\begin{array}{l}\text { Growing market introduces diminishing } \\
\text { returns. }\end{array}$ & + \\
Organizational Readiness & & + \\
Size (H4) & Positive effect on probability of entry. \\
Product fit categories (H5) & Increases probability of entry. \\
External Influences & \\
Density (H6) & $\begin{array}{l}\text { Positive effect on probability of entry. } \\
\text { Competitive effects introduce diminishing } \\
\text { Density Sq. (H6) }\end{array}$ & $\begin{array}{l}\text { returns. } \\
\text { Increases probability of entry. }\end{array}$ \\
\hline
\end{tabular}




\section{TABLE II}

Descriptive statistics and correlations

\begin{tabular}{|c|c|c|c|c|c|c|c|c|c|c|c|}
\hline Variables & Mean & $\begin{array}{l}\text { Standard } \\
\text { Deviation }\end{array}$ & 1 & 2 & 3 & 4 & 5 & 6 & 7 & 8 & 9 \\
\hline \multicolumn{12}{|c|}{ Fixed Covariates $(n=392)$} \\
\hline 1. Internet Store & .47 & .50 & 1.000 & & & & & & & & \\
\hline 2. Sales (\$ mil.) & 4375.72 & 14256.18 & 0.040 & 1.000 & & & & & & & \\
\hline 3. Product fit & .32 & .47 & 0.042 & -0.043 & 1.000 & & & & & & \\
\hline 4. Public & .81 & .40 & 0.023 & 0.087 & 0.030 & 1.000 & & & & & \\
\hline 5. International & .17 & .38 & -0.039 & 0.076 & -0.138 & 0.130 & 1.000 & & & & \\
\hline \multicolumn{12}{|c|}{$\begin{array}{l}\text { Time-Varying Covariates }- \text { firm-quarter } \\
\text { observations }(n=10251)\end{array}$} \\
\hline 6. Market growth & 549.34 & 338.90 & 0.061 & 0.019 & 0.013 & 0.020 & -0.015 & 1.000 & & & \\
\hline 7. NASDAQ growth & 43.02 & 386.97 & 0.019 & 0.019 & 0.015 & 0.015 & -0.016 & 0.598 & 1.000 & & \\
\hline 8. Advertising & 8.34 & 3.78 & 0.049 & -0.018 & -0.020 & -0.004 & 0.016 & 0.101 & 0.044 & 1.000 & \\
\hline 9. Density & 10.28 & 15.47 & 0.055 & -0.071 & 0.401 & 0.022 & 0.004 & -0.137 & -0.142 & 0.142 & 1.000 \\
\hline
\end{tabular}




\section{TABLE III}

One, two, and five-year entry rates

\begin{tabular}{|c|c|c|c|c|c|c|c|}
\hline & All & Big & Small & Public & Private & Product fit & No product fit \\
\hline 1 year & $2.5 \%$ & $4.1 \%$ & $2 \%$ & $2.5 \%$ & $2.6 \%$ & $4.8 \%$ & $1.5 \%$ \\
\hline 2 years & $4.6 \%$ & $8.2 \%$ & $3.4 \%$ & $4.4 \%$ & $5.3 \%$ & $9.6 \%$ & $2.2 \%$ \\
\hline 5 years & $29.3 \%$ & $41.8 \%$ & $25.1 \%$ & $30.6 \%$ & $23.7 \%$ & $44 \%$ & $22.1 \%$ \\
\hline \multicolumn{2}{|c|}{ Log-rank test for equality } & \multicolumn{2}{|c|}{$\operatorname{chi} 2(1)=24.60$} & \multicolumn{2}{|c|}{$\operatorname{chi} 2(1)=6.04$} & \multicolumn{2}{|c|}{$\operatorname{chi} 2(1)=23.42$} \\
\hline \multicolumn{2}{|c|}{ of survivor functions } & \multicolumn{2}{|c|}{$\operatorname{Pr}>\operatorname{chi} 2=0.000$} & \multicolumn{2}{|c|}{$\operatorname{Pr}>\operatorname{chi} 2=0.014$} & \multicolumn{2}{|c|}{$\operatorname{Pr}>\operatorname{chi} 2=0.000$} \\
\hline
\end{tabular}




\section{TABLE IV}

Coefficient estimates from the discrete hazard models

\begin{tabular}{|c|c|c|c|c|}
\hline \multirow[b]{2}{*}{ Determinant Factors } & \multicolumn{2}{|c|}{$\begin{array}{c}\text { Model } 1 \\
\text { Logit link }\end{array}$} & \multicolumn{2}{|c|}{$\begin{array}{c}\text { Model } 2 \\
\text { Cloglog link }\end{array}$} \\
\hline & Coefficient & $\begin{array}{c}\text { Standard } \\
\text { error }\end{array}$ & Coefficient & $\begin{array}{l}\text { Standard } \\
\text { error }\end{array}$ \\
\hline Market growth rate $(\mathrm{H} 1)$ & 0.0005 & 0.0004 & 0.0005 & 0.0003 \\
\hline NASDAQ growth rate $(\mathrm{H} 2)$ & -0.0002 & 0.0002 & -0.0002 & 0.0002 \\
\hline Advertising (H3) & -0.2500 & $0.1429 *$ & -0.2484 & $0.1419^{*}$ \\
\hline Advertising Sq. (H3) & 0.0093 & $0.0051^{*}$ & 0.0092 & $0.0051 *$ \\
\hline Size $(\mathrm{H} 4)$ & 0.1327 & $0.0312 * * *$ & 0.1259 & $0.0279 * * *$ \\
\hline Product fit categories (H5) & 0.7339 & $0.2033 * * *$ & 0.7230 & $0.1998 * * *$ \\
\hline Density (H6) & 0.0501 & $0.0171 * * *$ & 0.0490 & $0.0168 * * *$ \\
\hline Density Sq. (H6) & -0.0010 & $0.0003 * * *$ & -0.0010 & $0.0003 * * *$ \\
\hline Public (H7) & 0.4989 & $0.2314 * *$ & 0.4966 & $0.2275^{* *}$ \\
\hline International & -1.0906 & $0.2668 * * *$ & -1.0750 & $0.2639 * * *$ \\
\hline Y2 & -0.2142 & 0.5162 & -0.2097 & 0.5127 \\
\hline Y3 & 0.9383 & $0.4491 * *$ & 0.9309 & $0.4450 * *$ \\
\hline Y4 & 1.5132 & $0.5620 * * *$ & 1.5054 & $0.5587 * * *$ \\
\hline Y5 & 2.5723 & $0.5808 * * *$ & 2.5322 & $0.5757 * * *$ \\
\hline Y6 & 2.6112 & $0.5954 * * *$ & 2.5897 & $0.5899 * * *$ \\
\hline Y7 & 2.3483 & $0.5684 * * *$ & 2.3256 & $0.5626 * * *$ \\
\hline Y8 & 1.5165 & $0.5762 * * *$ & 1.5048 & $0.5708 * * *$ \\
\hline Constant & -5.4037 & $0.7143 * * *$ & -5.3901 & $0.7024 * * *$ \\
\hline Log-Lik Full Model: & -82 & & -83 & 2.65 \\
\hline
\end{tabular}




\section{TABLE V}

Coefficient Estimates from the SPD Model

\begin{tabular}{|c|c|c|}
\hline \multirow[b]{2}{*}{ Determinant Factors } & \multicolumn{2}{|c|}{ SPD Model } \\
\hline & Coefficient & Standard error \\
\hline Market growth rate $(\mathrm{H} 1)$ & 0.0005 & 0.0004 \\
\hline NASDAQ growth rate $(\mathrm{H} 2)$ & -0.0002 & 0.0002 \\
\hline Advertising $(\mathrm{H} 3)$ & -0.2484 & 0.1919 \\
\hline Advertising Sq. (H3) & 0.0092 & 0.0070 \\
\hline Size $(\mathrm{H} 4)$ & 0.1259 & $0.0252 * * *$ \\
\hline Product fit categories (H5) & 0.7229 & $0.2015 * * *$ \\
\hline Density (H6) & 0.0490 & $0.0170 * * *$ \\
\hline Density Sq. (H6) & -0.0010 & $0.0003 * * *$ \\
\hline Public (H7) & 0.4966 & $0.2180 * *$ \\
\hline International & -1.0750 & $0.2643 * * *$ \\
\hline Y2 & -0.2097 & 0.5142 \\
\hline Y3 & 0.9308 & 0.7021 \\
\hline Y4 & 1.5054 & $0.7847 *$ \\
\hline Y5 & 2.5322 & $0.8314 * * *$ \\
\hline Y6 & 2.5897 & $0.8711 * * *$ \\
\hline Y7 & 2.3256 & $0.8309 * * *$ \\
\hline Y8 & 1.5047 & $0.7283 * *$ \\
\hline Constant & -5.3901 & $0.7251 * * *$ \\
\hline$c \mathrm{p}(\mathrm{E}=0)$ & $1.132 \mathrm{e}-08$ & $1.131 \mathrm{e}-07$ \\
\hline Log-Lik Full Model: & \multicolumn{2}{|c|}{-832.65} \\
\hline
\end{tabular}




\section{References}

Aaker, D. A. and Day, G.S. (1986), "The perils of high-growth markets," Strategic Management Journal, Vol. 7 No. 5, pp. 409-21.

Allison, P. (1995), Survival Analysis Using the SAS System, SAS Institute, Cary, NC.

Banerjee, A. V. (1992), “A simple model of herd behavior”, The Quarterly Journal of Economics, Vol. 107 No. 3, pp. 797-817.

Barnett, W. P. (1990), “The organizational ecology of a technological system”, Administrative Science Quarterly, Vol. 35 No.1, pp. 31-60.

Bikhchandani, S., Hirshleifer, D. and Welch, I. (1992), “A theory of fads, fashion, custom, and cultural change as informational cascade", Journal of Political Economy, Vol. 100 No.5, pp. 992-1026.

Cleves, M.A., Gould, W.W. and Gutierrez, R.G. (2002), An Introduction to Survival Analysis Using Stata, Stata Press, College Station, TX.

De Figueiredo, J. (2000), "Finding sustainable profitability in electronic commerce", Sloan Management Review, Vol. 41 No. 4, pp. 41-52.

Dekimpe, M. G., Van de Gucht, L. M., Hanssens, D.M. and Powers, K.I. (1998), "Long-run abstinence after treatment for narcotics abuse: what are the odds?" Management Science, Vol. 44 No.11,1, pp. 1478-92.

Delacroix, J. and Rao, H. (1994), "Externalities and ecological theory: unbundling density dependence", in Singh, J. V. and Baum, J.A.C. (Eds.), Evolutionary Dynamics of Organizations, Oxford, England: Oxford University Press, pp. 255-68.

Geroski, P. A. (1995), "What do we know about entry?", International Journal of Industrial Organization, Vol. 13 No. 4, pp. 421-40.

Geroski, P. A. and Mazzucato, M. (2001), "Modeling the dynamics of industry populations", International Journal of Industrial Organization, Vol. 19 No. 7, pp. 1003-22.

Ghosh, S. (1998), "Making business sense of the Internet," Harvard Business Review, Vol. 76 No. 2, pp. 126-35.

Golder, P. and Tellis, G. (2004), "Going, going, gone: cascades, diffusion, and turning points of the product life cycle", Marketing Science, Vol. 23 No. 2, pp. 207-18.

Grandon, E. E. and Pearson, M. J. (2004), "Electronic commerce adoption: an empirical study of small and medium US businesses", Information \& Management, Vol. 42 No. 1, pp. 197216.

Greve, H. R. (1996), "Patterns of competition: the diffusion of a market position in radio broadcasting", Administrative Science Quarterly, Vol. 41 No. 1, pp. 29-60.

Hannan, M. T. and Freeman, J. (1989), Organizational Ecology ${ }_{2}$ Harvard University Press, Cambridge, Mass.

Hannan, M. T. and Carroll, G. R. (1992), Dynamics of Organizational Populations: Density, Competition and Legitimation, Oxford University Press, New York. 
Hart, C., Doherty, N. and Ellis-Chadwick, F. (2000), "Retailer adoption of the Internet: Implications for retail marketing", European Journal of Marketing, Vol. 34 No. 8, pp. 954-74.

Hitt, L. M. and Brynjolfsson, E. (1996), "Productivity, business profitability, and consumer surplus: three different measures of information technology value," MIS Quarterly, Vol. 20 No. 2, pp. 121-42.

Hoffman, D.L. and Novak, T.P. (1996), "Marketing in hypermedia computer-mediated environments: conceptual foundations," Journal of Marketing, Vol. 60 No. 3, pp. 50-68.

Hunter, S. D. (2003), "Information technology, organizational learning, and the market value of the firm", Journal of Information Technology Theory and Application, Vol. 5 No. 1, pp. $1-28$.

Iacovou, C.L., Benbasat, I. and Dexter, A.S. (1995), "Electronic data interchange and small organizations: adoption and impact of technology”, MIS Quarterly, Vol. 19 No. 4, pp. $465-85$.

Jenkins, S.P. (2001), "SPSURV: Stata module to fit split population survival ('cure') model”, Available http://econpapers.repec.org/software/bocbocode/s418601.htm.

Jenkins, S.P. (1995), "Easy estimation methods for discrete-time duration models", Oxford Bulletin of Economics and Statistics, Vol. 57 No. 1, pp. 129-38.

Jovanovic, B. and MacDonald, G. (1994), "The life-cycle of a competitive industry", Journal of Political Economy, Vol. 102 No. 2, pp. 322-47.

Keeney, R. (1999), “The value of Internet commerce to the customer", Management Science, Vol. 45 No.4, pp. 533-42.

Klepper, S. (2002), "Firm survival and the evolution of oligopoly", The Rand Journal of Economics, Vol. 33 No. 1, pp. 37-61.

Lal, R. and Sarvary, M. (1999), "When and how is the Internet likely to decrease price competition?", Marketing Science, Vol. 18 No. 4, pp. 485-503.

Latcovich, S. and Smith, H. (2001), "Sinking the Internet: Pricing, sunk costs, and market structure online", Oxford Review of Economic Policy, Vol. 17 No. 2, pp. 217-34.

Lieberman, M. and Asaba, S. (2005), "Why do firms imitate each other?”, Forthcoming, Academy of Management Review.

Mahajan, V., Srinivasan, R. and Wind, J. (2002) "The dot.com retail failures of 2000: were there any winners?", Journal of the Academy of Marketing Science, Vol. 30 No. 4, pp. 474-86.

Maug, E. (2001) "Ownership structure and the life-cycle of the firm: a theory of the decision to go public", European Finance Review, Vol. 5 No. 3, pp. 167-200.

O'Callaghan, R., Kaufman, J. \& Konsynski, B.R. (1992), „Adoption correlates and share effects of electronic data interchange systems In marketing channels", Journal of Marketing,. Vol. 56 No. 2, pp. 45-56.

Ozsomer, A. and Cavusgil, S. T. (1999), "A dynamic analysis of market entry rates in a global industry: a community ecology perspective", European Journal of Marketing, Vol. 33 No. 11/12, pp. 1038- 63. 
Sutton, J. (1991), Sunk Costs and Market Structure: Price Competition, Advertising and the Evolution of Concentration, MIT Press, Cambridge, Mass.

Wu, F., Mahajan, V., and Balasubramanian, S. (2003), "An analysis of e-business adoption and its impact on business performance", Journal of the Academy of Marketing Science, Vol. 31 No. 4, pp. 425-47.

Zhu, K., Kraemer, K. and Xu, S. (2003), "E-business adoption by European firms: a crosscountry assessment of the facilitators and inhibitors," European Journal of Information Systems, Vol. 12, No. 4, pp. 251-68. 
Notes

${ }^{1}$ This is the US spelling of "tyre" in British English.

${ }^{2}$ http://www.freelunch.com/

${ }^{3}$ One problem with the program estimating the SPD model is that the estimation of robust standard errors adjusting for the grouping of dependent observations is infeasible. This can cause imprecise estimation of the standard errors. Since the results of the cloglog estimation in Table IV report robust standard errors, they are different from the standard errors reported in Table V. 